
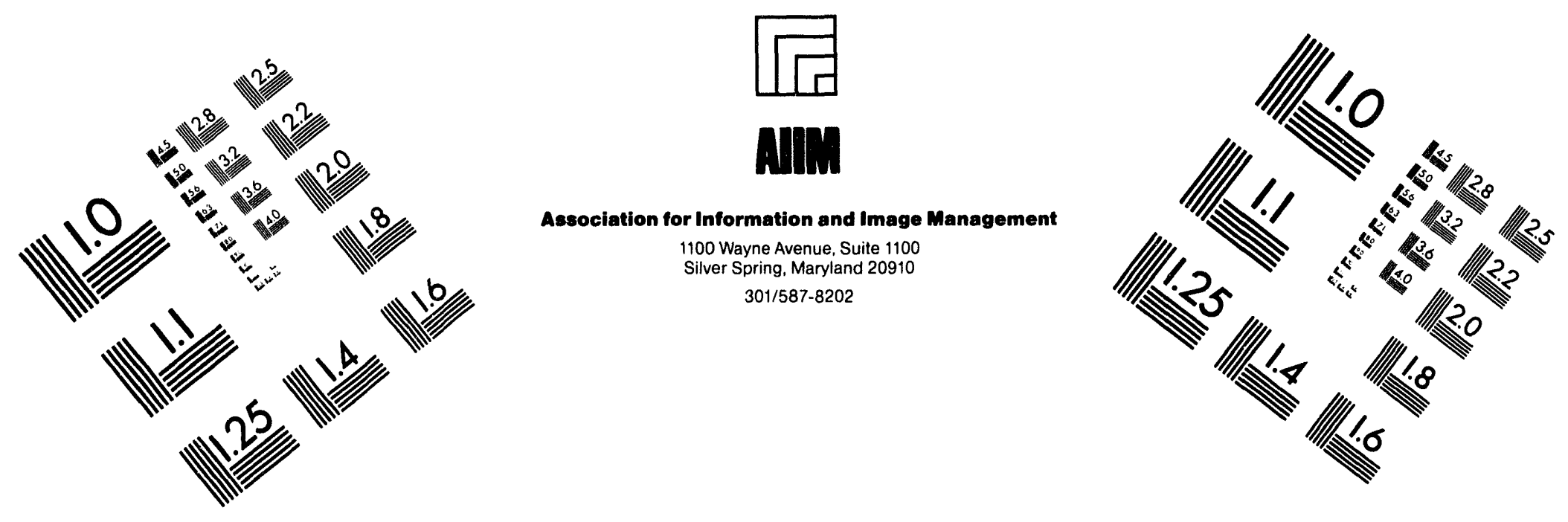

Centimeter

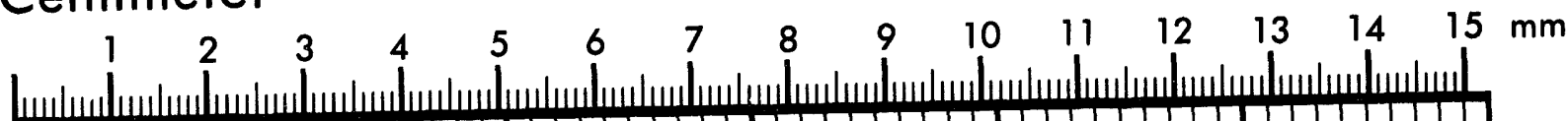
${ }_{1}$ Inches
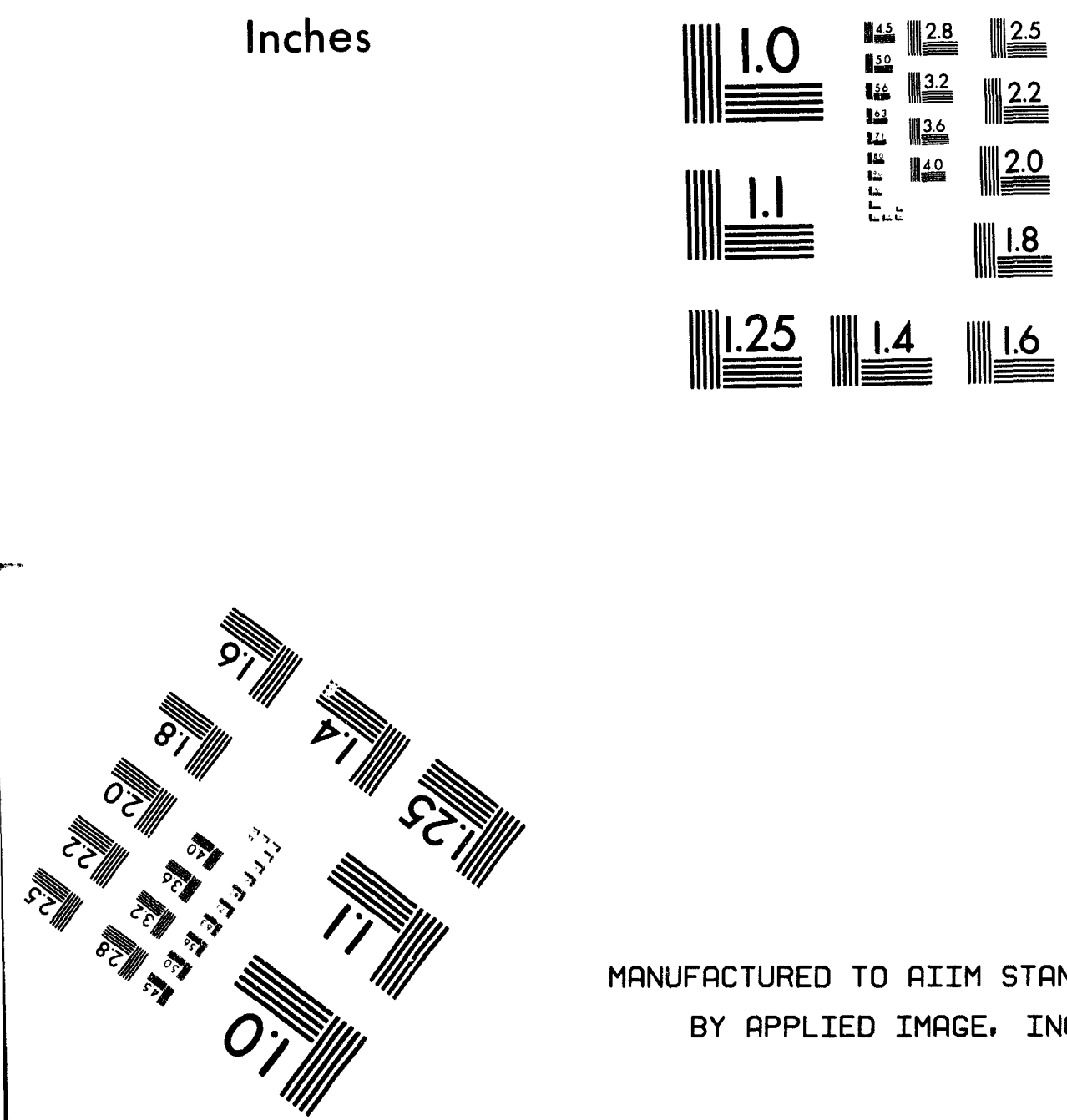

MANUFACTURED TO AIIM STANDARDS

BY APPLIED IMAGE, INC.

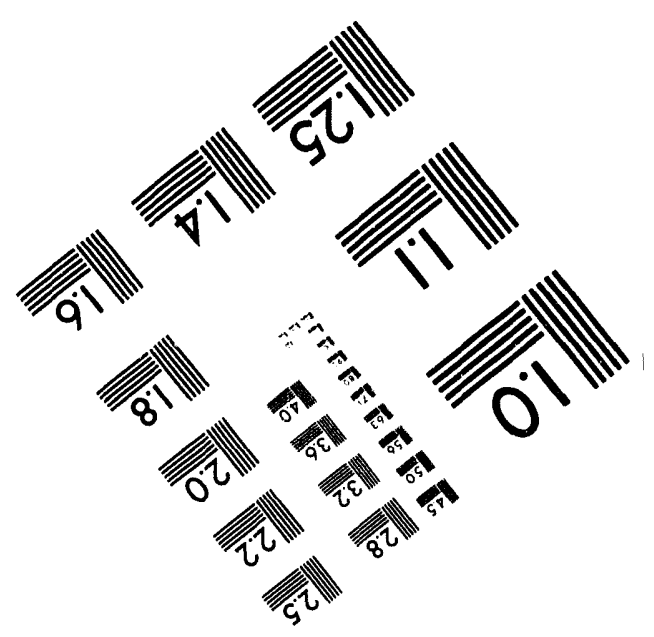



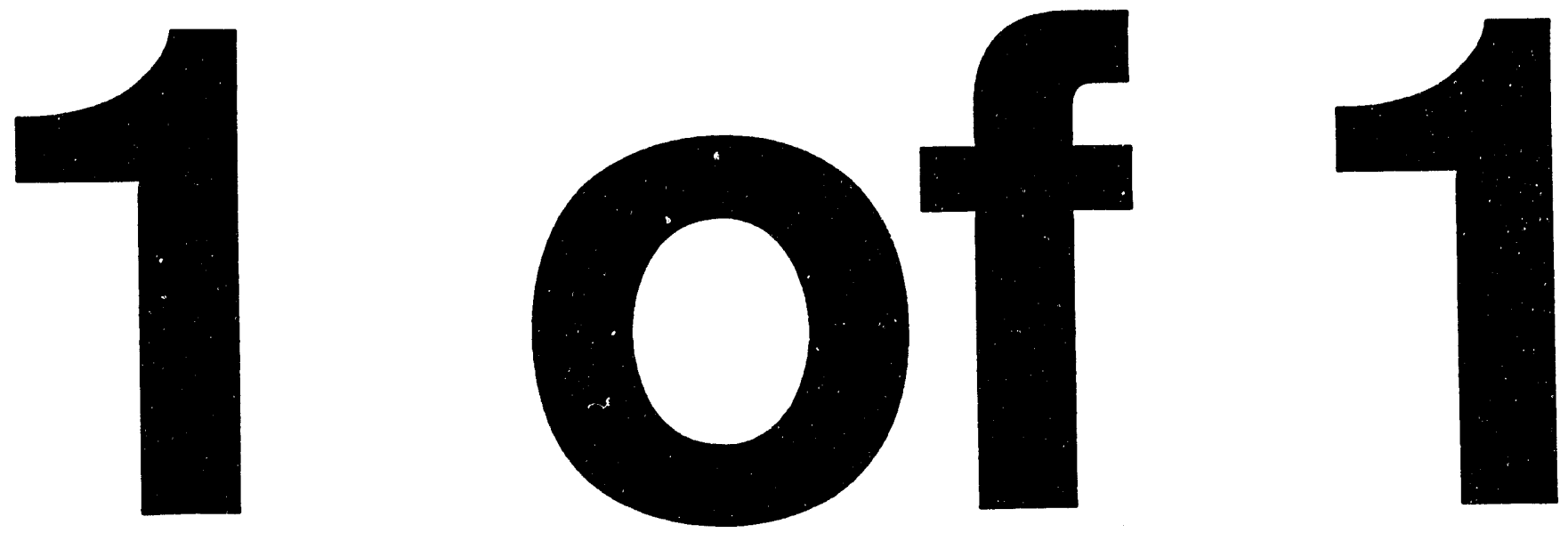


\title{
COMPARISON OF THE UNIQUE MOBILITY AND DOE- DEVELOPED AC ELECTRIC DRIVE SYSTEMS
}

\author{
G. H. Cole
}

January 1993

EG\&G Idaho, Inc.

Idaho Falls, Idaho 83415

Prepared for the

U. S. Department of Energy

Field Office, Idaho

Under Contract No. DE-AC07-76ID01570

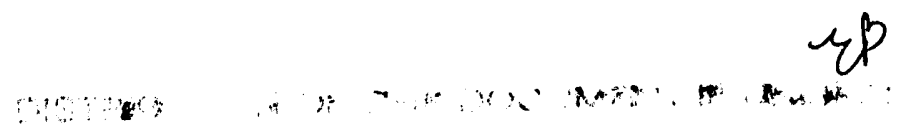




\section{ABSTRACT}

A comparison was made between the most recent DOE-developed $A C$ electric vehicle drive systems and that which is independently under development by Unique Mobility of Golden, Colorado. The DOE-developed AC systems compared in this study are the Single-Shaft Electric Propulsion System (ETX-II) developed by Ford Motor Company and General Electric Company under contract number DE-AC07-85NV10418, the Dual-Shaft Electric Propulsion (DSEP) System developed by Eaton Corporation under contract number DOE-AC08-84NV-10366, and the anticipated results of the Modular Electric Vehicle (MEV) system currently being developed by Ford and General Electric under contract number DE-AC07-90ID13019. The Unique Mobility brushless DC electric vehicle drive system represents their latest electric drive technology and is being developed in cooperation with BMW Technik Gmbh of Germany.

Comparisons of specific volume, specific weight, efficiency and expected vehicle performance are made of the different systems based upon measured system performance data where available. One conclusion presented is that the Unique Mobility drive system under development with BMW appears to provide comparable performance to the AC systems studied. 


\section{CONTENTS}

Introduction ...................... 1

Power vs weight . . . . . . . . . . . . . . 7

Power vs Volume ....................... . . . 9

Torque .............................. 11

Efficiency ........................ 15

MEVP Trade-offs ......................... 19

Vehicle Performance ................ 21

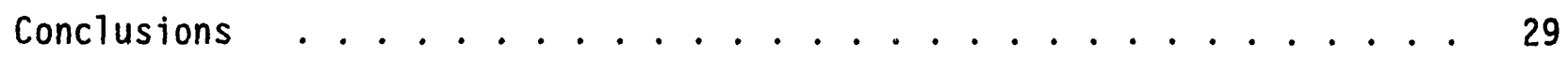

References .................. 31

\section{FIGURES}

1. Characteristic electric drive system curves ... . . . . . . 4

2. Normalized weight comparison of EV drive systems . . . . . . . 8

3. Volumetric comparison of EV drive systems . . . . . . . . . 10

4. Peak torque normalized by system weight . . . . . . . . 12

5. Peak torque normalized by system peak power . . . . . . . . . 13

6. Comparison of system efficiencies at peak torque . . . . . . 16

7. Comparison of system efficiencies at $50 \%$ of peak torque . . . . . 17

8. Comparison of system efficiencies at $25 \%$ of peak torque ...... 18

9. Maximum torque-speed envelope of the scdled motors used in the simulation ................... 23

10. Peak power versus speed characteristics of the scaled motors used in the simulation .................. 24

11. Acceleration of a hypothetical vehicle using each of the electric drive system technologies . . . . . . . . . . 25

12. Maximum effort acceleration comparison of technologies in a hypothetical vehicle ................ 26 


\section{TABLES}

1. Comparison of selected Unique Mobility and DOE AC electric drive system

2. Assumed BMW-El vehicle characteristics used in simulation for comparing electric drive systems

3. Parameters used in scaling each of the motors to the simulated vehicle

4. Comparison of drive system technologies in a hypothetical vehicle 


\section{COMPARISON OF THE UNIQUE MOBILITY AND DOE-DEVELOPED AC ELECTRIC DRIVE SYSTEMS}

\section{INTRODUCTION}

Unique Mobility, Inc. of Golden, Co currently has several electric drive systems available for purchase. These drive systems range in power from $3.8 \mathrm{~kW}$ motor/controller systems used in solar powered vehicles, to larger (20-63 kW) systems suitable for passenger car and light truck applications. Unique Mobility motors are brushless DC permanent magnet (Neodymium Iron Boron) machines having a large number of poles in the stator. These motors offer 4 quadrant operation, regeneration to zero speed, closed loop speed control and high constant power density over a wide speed range. Several winding configurations are available in many of the motors offered.

Unique Mobility currently has an effort with BMW to develop a $32 \mathrm{~kW}$ electric drive system for the BMW-El electric car. This development effort is wel1 underway with prototype hardware being tested at BMW. Unique Mobility considers the BMW drive system to be representative of the latest status of their techriology, while the systems offered for sale represent a mature technology status of at least two years ago. The BMW system is the first Unique Mobility drive to offer field weakening and produces high torque at low speeds. Unique Mobility provided actual test data on this system for use in this study. Information on this system is presented below to provide the state-of-the-art status of Unique Mobility's electric drive technology.

Recent product improvement efforts at Unique Mobility are aimed at manufacturing processes to reduce motor cost. Currently they are developing stators using powder metallurgy techniques and rotors utilizing epoxy bonding.

The purpose of this analysis is to compare the Unique Mobility technology to the DOE developed AC drivelines. Therefore, only the larger drive systems from Unique Mobility are compared. Table 1 provides a comparison of the larger Unique Mobility systems to the DOE developed systems. The characteristic motor curves (peak torque vs motor speed) for the 
Table 1. Comparison of selected Unique Mobility and DOE AC electric drive systems.

\begin{tabular}{|c|c|c|c|c|c|c|c|c|c|c|}
\hline & \multicolumn{7}{|c|}{ Unique Mobility Electric Drive Systems } & \multicolumn{3}{|c|}{ DOE AC Systems } \\
\hline \multicolumn{11}{|c|}{ Motor Data } \\
\hline Mode 1: & SR218E & SR218L & SR180LC & SR180L & SR180E & BMW & $\begin{array}{r}\text { Adv. } \\
\text { BMW }\end{array}$ & ETX-II & DSEP & $\begin{array}{l}\text { MEV-75 } \\
\text { (est.) } \\
\end{array}$ \\
\hline weight, $\mathrm{kg}$ & 48.1 & 49.9 & 20.0 & 25.9 & 23.6 & 36.3 & 36.3 & 50.8 & 90 & 59.0 \\
\hline diameter, in. & 12.3 & 12.3 & 9.5 & 11.0 & 11.0 & NA & NA & 8.77 & 10 & 8.77 \\
\hline length, in. & 9.4 & 9.4 & 5.3 & 9.4 & 9.4 & NA & NA & 7.5 & 8.7 & 7.5 \\
\hline volume, in ${ }^{3}$ & 1106 & 1106 & 376 & 892 & 892 & 798 & 798 & 453 & 683 & 453 \\
\hline \multicolumn{11}{|c|}{ Controller/Inverter Data } \\
\hline Mode 1: & CR20-300 & CR20-300 & CR20-300 & CR20-300 & CR20-300 & BMW & $\begin{array}{c}\text { Adv. } \\
\text { BMW }\end{array}$ & ETX-II & DSEP & $\begin{array}{r}\text { MEV-75 } \\
\text { (est.) } \\
\end{array}$ \\
\hline weight, $\mathrm{kg}$ & 20.0 & 20.0 & 21.8 & 21.8 & 21.8 & 19.4 & 12.5 & 36.3 & 32.2 & 23.6 \\
\hline volume, in ${ }^{3}$ & 2761 & 2761 & 2761 & 2761 & 2761 & 1283 & 1109 & 2756 & 6713 & 2356 \\
\hline $\begin{array}{l}\text { Nominal Input Voltage, vdc } \\
\text { (Voltage at which motor is } \\
\text { rated, vdc) }\end{array}$ & $\begin{array}{l}200 \\
\text { (NA) }\end{array}$ & $\begin{array}{l}200 \\
(\mathrm{NA}) \\
\end{array}$ & $\begin{array}{l}200 \\
(N A) \\
\end{array}$ & $\begin{array}{l}200 \\
\text { (NA) } \\
\end{array}$ & $\begin{array}{l}195 \\
\text { (NA) } \\
\end{array}$ & $\begin{array}{r}200 \\
(180) \\
\end{array}$ & $\begin{array}{r}200 \\
(180) \\
\end{array}$ & $\begin{array}{r}204 \\
(150) \\
\end{array}$ & $\begin{array}{l}170 \\
\text { (NA) } \\
\end{array}$ & $\begin{array}{r}336 \\
(255) \\
\end{array}$ \\
\hline \multicolumn{11}{|c|}{ Rated system peak power, $\mathrm{kW}$} \\
\hline & 63 & 60 & 24.6 & 35 & 20 & 32 & 32 & 52.2 & 44.8 & 56.0 \\
\hline
\end{tabular}

Comparative Parameters

\begin{tabular}{|c|c|c|c|c|c|c|c|c|c|c|}
\hline \multicolumn{11}{|c|}{$\mathrm{kg} / \mathrm{kW}$} \\
\hline Motor & 0.8 & 0.8 & 0.8 & 0.7 & 1.2 & 1.1 & 1.1 & 1.0 & 2.0 & 1.1 \\
\hline Controller/Inverter ${ }^{*}$ & 0.6 & 0.7 & 0.9 & 0.6 & 1.1 & 0.6 & 0.4 & 0.7 & 0.7 & 0.4 \\
\hline Total & 1.4 & 1.5 & 1.7 & 1.4 & 2.3 & 1.7 & 1.5 & 1.7 & 2.7 & 1.5 \\
\hline \multicolumn{11}{|c|}{$\mathrm{in}^{3} / \mathrm{kW}$} \\
\hline Motor & 18 & 18 & 15 & 25 & 45 & 25 & 25 & 9 & 15 & 8 \\
\hline Controller/Inverter & 44 & 46 & 112 & 79 & 138 & 40 & 35 & 53 & 150 & 42 \\
\hline Total & 61 & 64 & 127 & 104 & 183 & 65 & 60 & 61 & 165 & 50 \\
\hline
\end{tabular}

- Controller/Inverter power taken equal to motor output power. In some cases, the contoller/inverter can provide significantly higher power than that required by the motor at rated power. 
Unique Mobility/BMW system and the recent DOE AC systems (DSEP, ETX-II, and the MEV $75 \mathrm{Hp}$ drive) are shown in Figure 1. The MEV system performance is based on estimates produced during Phase I of the Modular Electric Vehicle Program while all other system characteristics represent actual measured performance. Generally speaking, the DOE AC systems operate at higher motor speeds than the Unique Mobility/BMW system. Speed range coupled with motor torque characteristics are important considerations when designing an electric vehicle since motor speed has bearing upon whether or not a multiple speed transmission (for a given motor peak power rating) is necessary to obtain the desired acceleration performance.

As noted from Table 1, the Unique Mobility systems are designed to operate at approximately the same nominal voltage as the ETX-II and DSEP systems, but lower than that of the MEV-75 system. Because electric vehicle drive systems must provide good performance throughout a range of voltage due to depression of the battery voltage when a load is applied, the battery voltage at which the motor and drive system must attain the rated power of the system is often taken to be significantly less than the nominal open circuit voltage of the battery. For these systems, the maximum power that can be attained at nominal battery voltage is significantly greater than the rated power of the system. This is the case with the ETX-II and MEV-75 drivelines for which the maximum power is approximately $30 \%$ higher than the rated power for the system. The comparisons made in this report are based on the rated power for the systems in all cases.

The ETX-II electric drive system was designed to provide rated power at $150 \mathrm{vdc}$, and the data presented in this report were taken at this voltage. Higher power and greater efficiency can be expected at higher battery voltages. It should also be noted that two inverters were developed in the ETX-II program, each utilizing different semiconductor technologies for the power switch devices. One was based on Darlington transistors and one was based on MOS Controlled Thyristors (MCTS). The data presented in this report used the Darlington transistor inverter. From the limited data on system performance utilizing the MCT inverter, 2-3 points in efficiency gain over the 


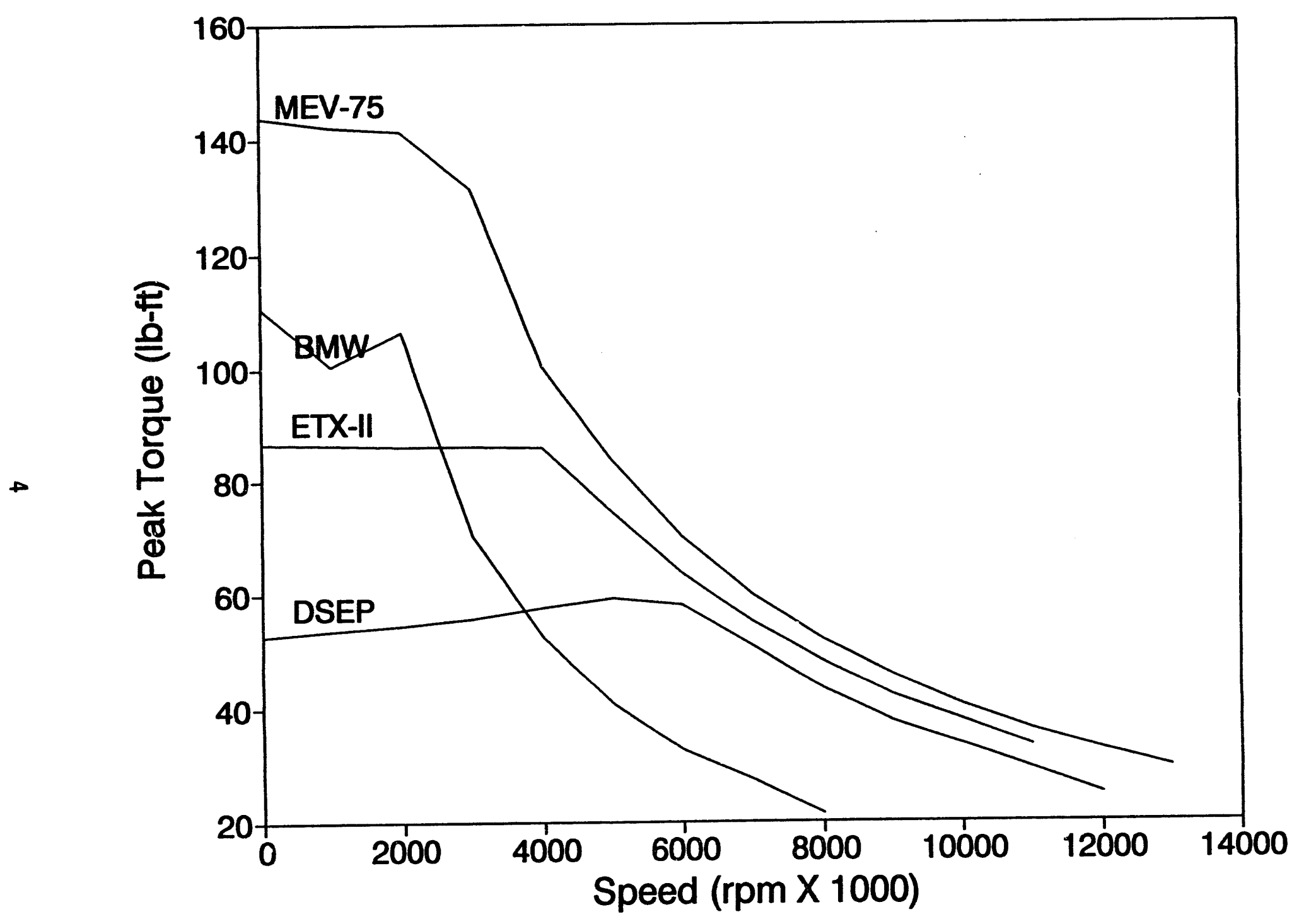

Figure 1. Characteristic electric drive system curves. 
Darlington transistor inverter can be expected at most speed-torque operating points.

The MEV-75 system information presented are based on calculations of system performance. The rated power and projected performance were calculated for $255 \mathrm{vdc}$, not the nominal battery voltage of $336 \mathrm{vdc}$. Test data for the MEV -75 has not been released by Ford and General Electric. Previous comparisons between the calculated performance made by General Electric and laboratory test data for the ETX-I and ETX-II systems were in excellent agreement. Therefore, it is anticipated that the performance projections made by General Electric for the MEV-75 system will prove equally accurate.

The data presented for the Unique Mobility/BMW system were taken utilizing a $180 \mathrm{v}, 0.200 \mathrm{ohm}$ power source representing expected performance using a sodium-sulfur battery. Therefore, unlike the ETX-II and MEV-75 data, these data were taken under a varying input voltage conditions. Data utilizing a $180 \mathrm{v}, 0$ ohm power source (constant voltage) were examined. In general, slightly higher efficiency (2-4 points) at most speed-torque points and greater power output in the constant power region (3-8 kW) were noted at these higher voltages.

The data presented for the DSEP system were taken using the nickel-iron battery developed in that program, which consisted of 28 Eagle-Picher NIF-170 modules. Information regarding the battery voltages under which the data were obtained is not available. However, like the Unique Mobility/BMW system these data were taken under varying voltage conditions. Utilizing test data obtained in the INEL Battery Test Laboratory, it is estimated that the battery represented power source characteristics ranging from $190 \mathrm{vdc}, 0.07 \mathrm{ohm}$ at $0 \%$ DOD to $165 \mathrm{vdc}, 0.09$ ohm at $80 \%$ DOD. 


\section{POWER VS WEIGHT}

Figure 2 shows the Unique Mobility drive systems (motors and controllers) and the DOE AC drives (motors and inverters) compared on a weight per unit power basis. The higher power 25-63 kW Unique Mobility systems are seen to have essentially the same specific power $(\mathrm{kg} / \mathrm{kW})$ as the ETX-II and MEV-75 systems developed by Ford and General Electric under DOE contracts. The values for the two Unique Mobility/BMW systems are based upon actual test data for the present $32 \mathrm{~kW}$ drive system (1abeled BMW), and for the next generation system resulting from on-going controller design improvements (1abeled ADV. BMW). 


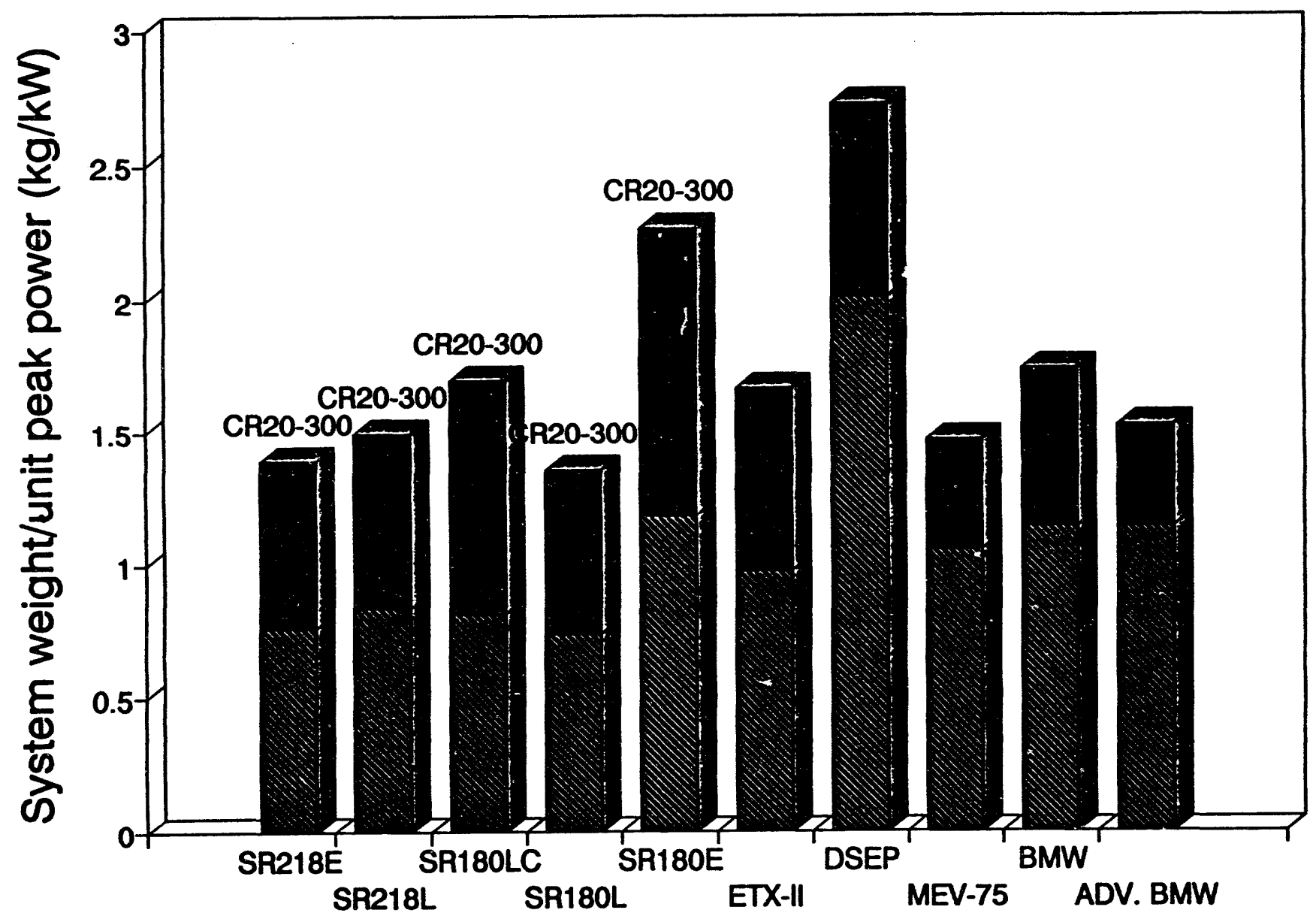

Motor Controller/inverter

Figure 2. Normalized weight comparison of EV drive systems. 


\section{POWER VS VOLUME}

Figure 3 shows the Unique Mobility drive systems (motors and controllers) and the DOE AC drives (motors and inverters) compared on a volume per unit power basis. It is shown that the 60-63 kW Unique Mobility and the $32 \mathrm{~kW}$ Unique Mobility/BMW systems have essentially the same volumetric specific power $\left(\mathrm{in}^{3} / \mathrm{kW}\right)$ as the DOE developed ETX-II and MEV-75 systems which represent 1990 and later technology. As mentioned above, the two Unique Mobility/BMW paramaters are based upon test data from their prototype system (1abeled BMW), and anticipated affects of controller design improvemenis (labeled ADV. BMW) currently under development. 


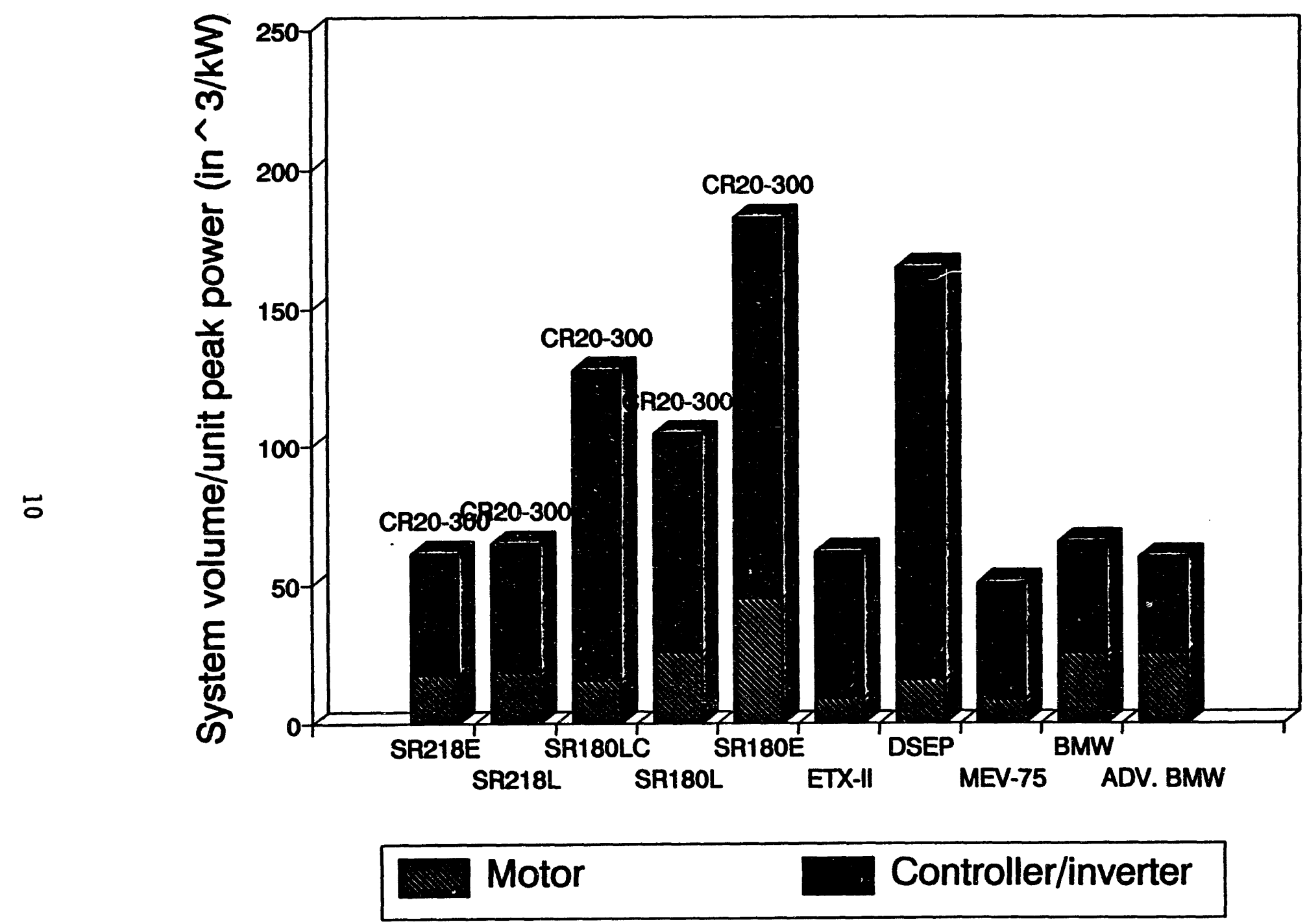

Figure 3. Volumetric comparison of EV drive systems. 


\section{TORQUE}

The peak torque of each of the systems of interest (and for which data were available) as a function of percent of maximum motor speed is shown in Figures 4 and 5 . Figure 4 normalizes the peak torque by the system weight while Figure 5 normalizes the peak torque by the rated (peak) power output of the system. The Unique Mobility system develops greater torque in the low speed regime than the DOE developed systems per both system weight and peak power output. However, it is noted that the Unique Mobility/BMW and MEV motors do not provide this peak torque over a substantial fraction of their speed range, and the torques fall off more rapidly than the earlier AC systems. It is also noted that the Unique Mobility/BMW motor has about twice the specific volume as the motors in the DOE AC systems. This is not surprising since generally speaking, motor torque is proportional to the motor diameter, and the motor volume is proportional to the square of this dimension. Thus increases in motor torque will result in second order increases in motor volume. The effect of motors of a given peak power rating having this characteristic used to power an electric vehicle with a single speed gear reduction to the wheels is to provide good low speed acceleration, whereas acceleration at medium to higher speeds will be noticeably slower by comparison to the low speed acceleration. 


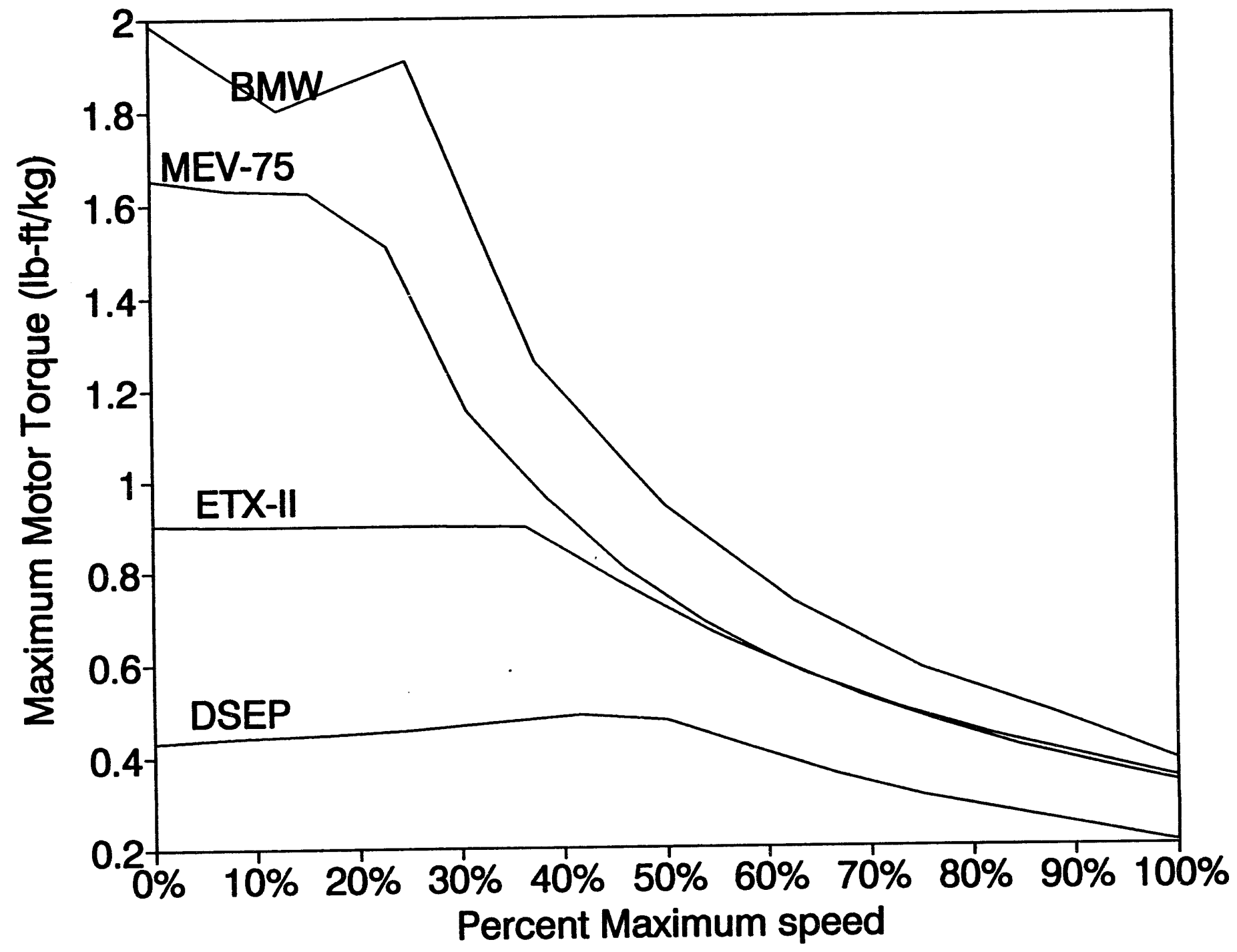

Figure 4. Peak torque normalized by system weight. 


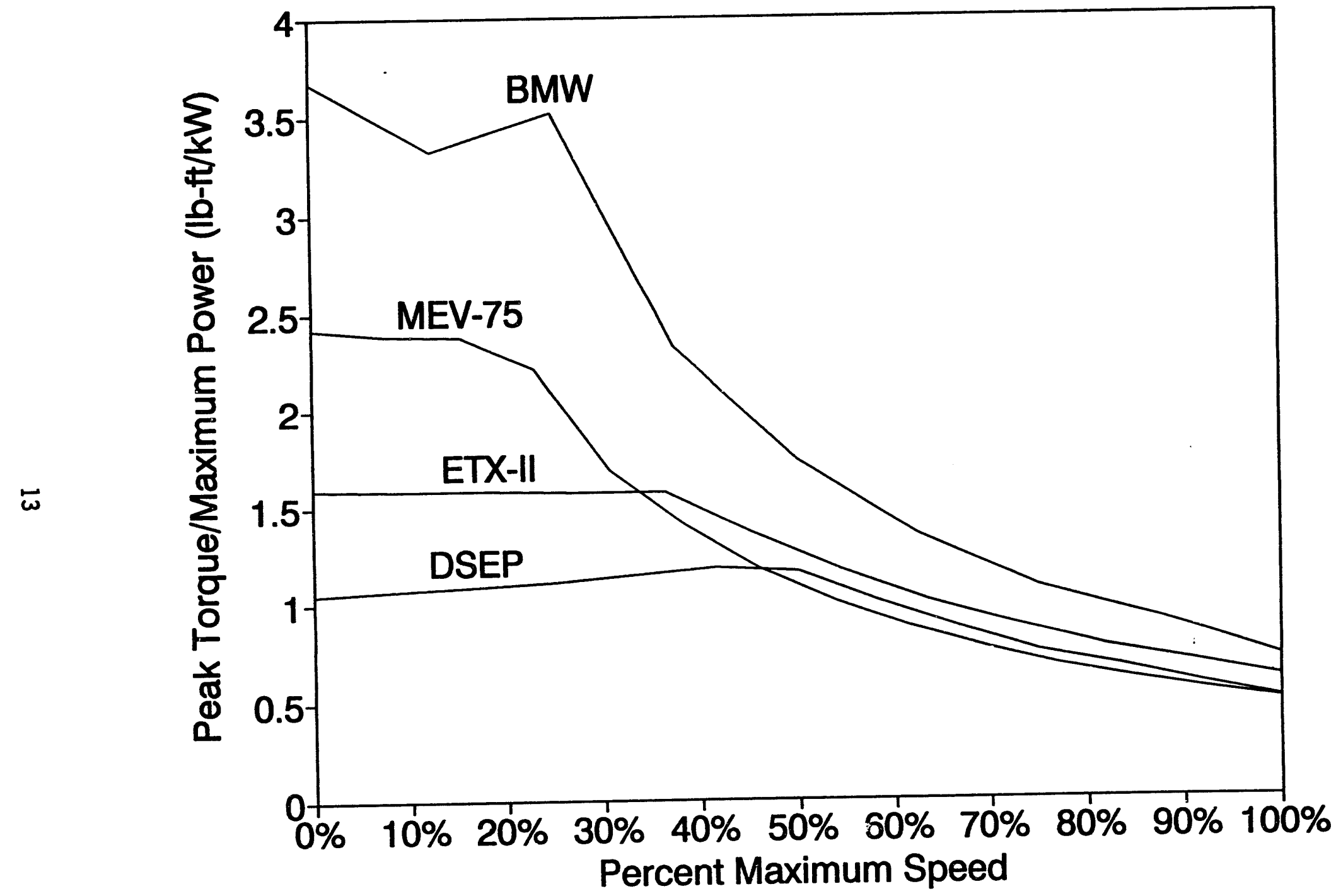

Figure 5. Peak torque normalized by system peak power. 


\section{EFFICIENCY}

The efficiencies of the systems of interest are presented in Figures 6 through 8. Figure 6 shows the efficiency of each system at maximum torque as a function of percent of maximum speed. The Unique Mobility system under development for BMW shows better efficiency at very low speeds $(10 \%$ of maximum) than the DOE AC systems, but lower efficiency than the state-of theart DOE AC systems (ETX-II and MEV) at all other speeds. Efficiency at peak torque, however, is of little concern in an electric vehicle application since the motor drive system is not frequently operated at these points.

A more meaningful comparison of system efficiencies is shown in Figures 7 and 8 , which graph the system efficiencies at $50 \%$ and $25 \%$ of the peak torque, respectively. In normal driving, the systems can be expected to operate more often in the lower torque regimes represented by these graphs. The Unique Mobility system under development for BMW has efficiency close to those of the DOE AC systems representing the latest technologies. In an actual electric vehicle application, which system would show the best efficiency cannot be determined since this characteristic is dependent upon the individual driveline and vehicle design, and the traction battery. Since there is significant flexibility in vehicle design trade-offs, and the efficiency characteristics of the Unique Mobility/BMW system are so similar to the ETX-II and MEV-75 systems, it can be said that efficiency alone (between the Unique/BMW system and the latest technology DOE AC systems) does not favor one particular technology. 


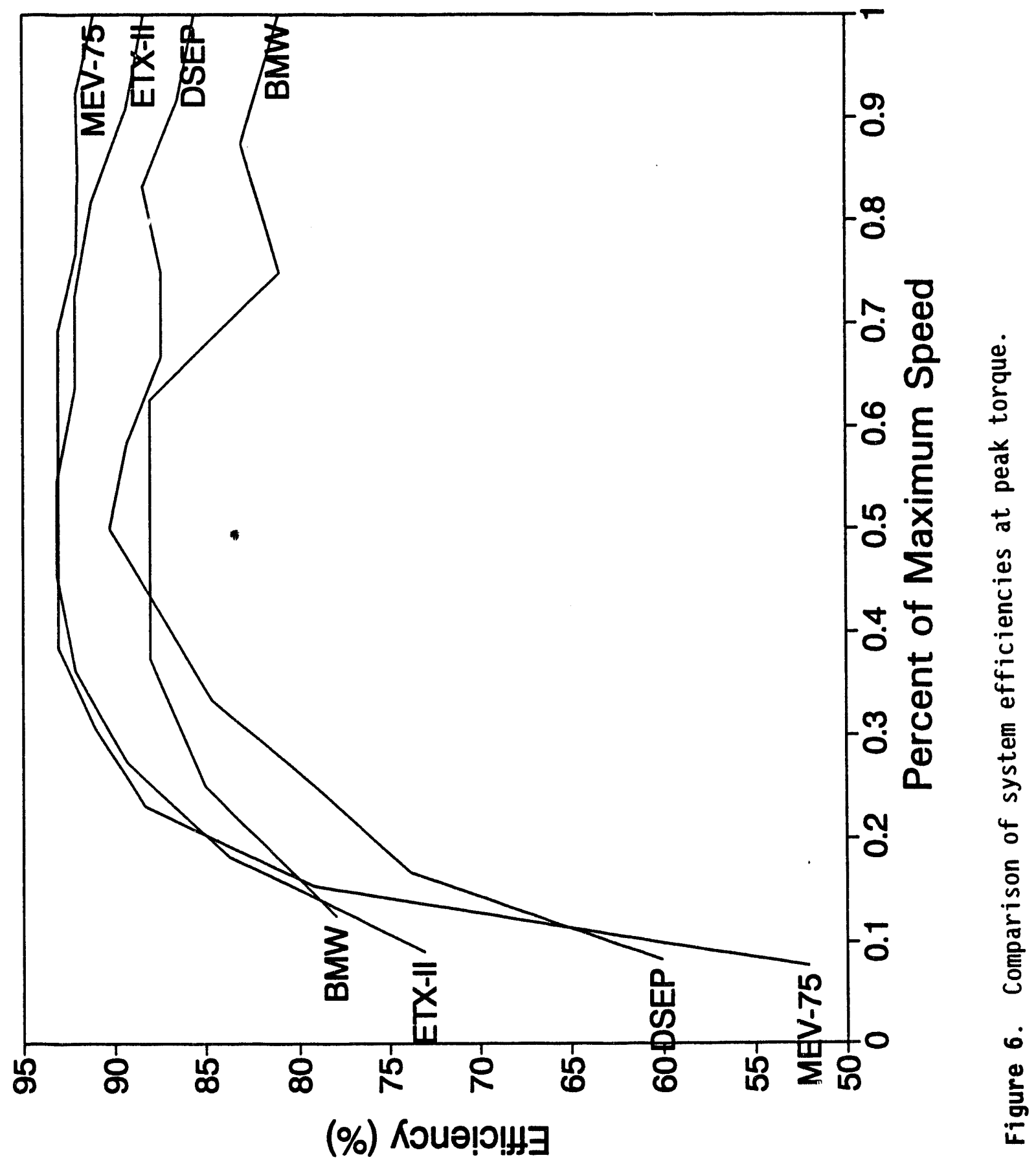




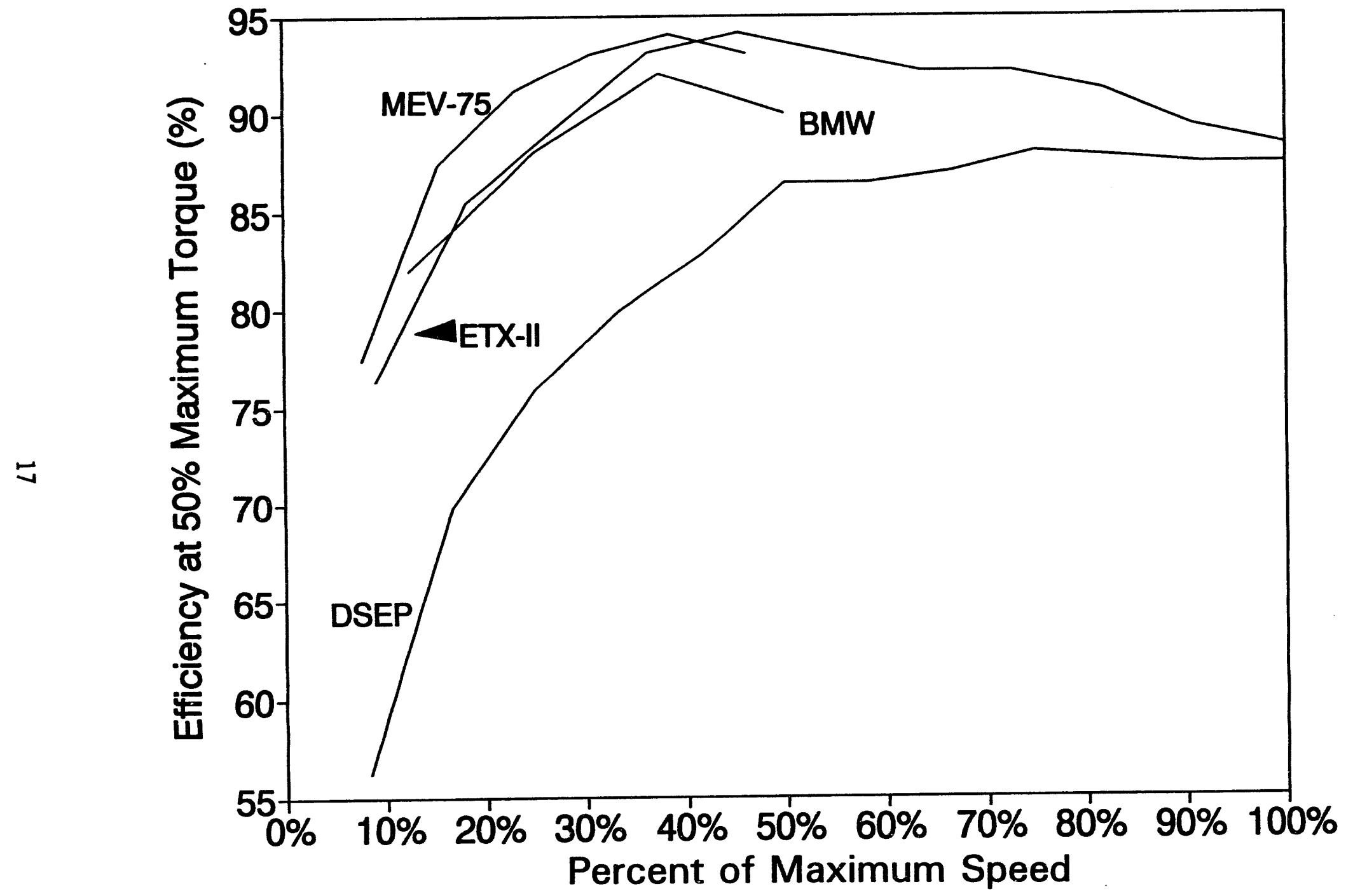

Figure 7. Comparison of system efficiencies at $50 \%$ of maximum torque. 


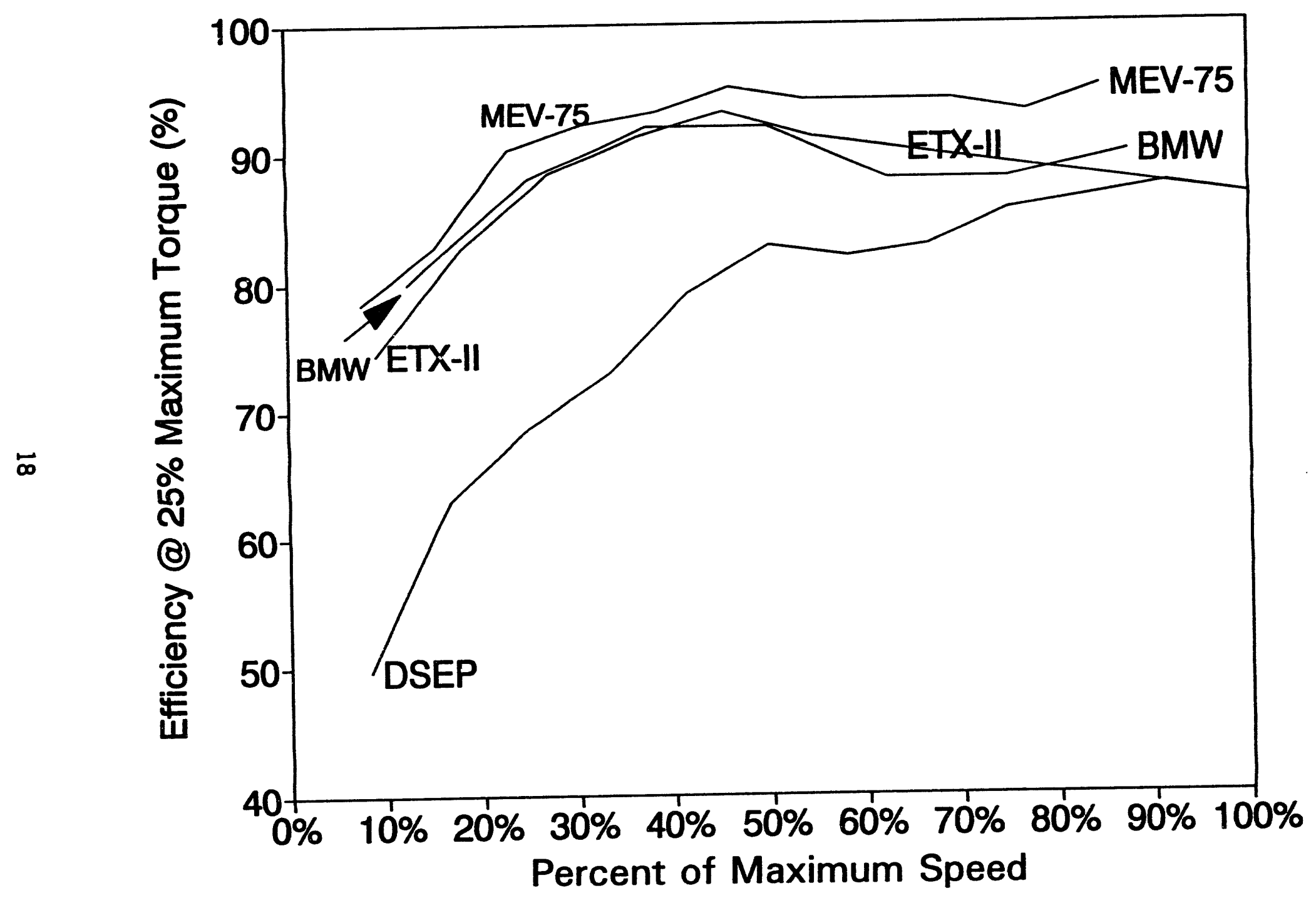

Figure 8. Comparison of system efficiencies at $25 \%$ of peak torque. 


\section{MEVP TRADE-OFFS}

During Phase I of the Modular Electric Vehicle Program, a trade-off study was performed to identify the most appropriate ( $A C$ or $D C$ ) drive system for development. This study was constrained to evaluating the relative merits of DC (defined as mechanically or brush commutated) systems and AC (similar to t:.e systems developed in the ETX-I and ETX-II) systems. The trade-off analys is considered relative component costs, component weights, efficiency, cooling methods, operating voltage, reliability, and system performance and the effects of these parameters on the vehicle design (e.g. the need for multi-speed transmission). The rationale and results of Ford's analysis is documented in the Modular Electric Vehicle Program (MEVP) Phase I Technical Report (March 1991) which concludes:

\footnotetext{
"When system cost advantages of weight and efficiency are included, there is a slight cost advantage for an ac drive today. When the additional advantages of reliability, motor size, and cooling are considered, there is a clear advantage to an ac drive."
}

Since the Unique Mobility technology is a brushless design and offers many advantages of the $A C$ systems cited in Ford's study, precisely how their system would fare if included in the MEV trade-off analys is cannot be easily determined without detailed cost information on both the motors and electronics packages.

As can be seen in Table 1, the Unique Mobility/BMW system is virtually on par with the newer DOE AC systems with respect to weight and volume per unit peak power. Motor cooling considerations are also similar for both the Unique Mobility and $A C$ systems. Both types of systems are brushless and can be designed for liquid cooling.

The Unique Mobility system would have a slight voltage disadvantage if considered in Ford's analysis. The MEV trade-off study concluded that system voltages in the 280 - 340 volt range resulted in minimum power switch costs. Unique Mobility systems operate around 200 volts, and would thus have a 
slightly higher cost associated with the power devices. However, it should be recognized that for electric vehicle applications, the selection of a system voltage must consider all other trade-offs. Unique Mobility's selection of a lower voltage than that chosen by Ford appears to be driven more by battery considerations than by any limitations inherent in the technology. If a drive system utilizing the technology employed by Unique Mobility were to be developed for the higher voltage range of the MEV-75 system, improvements in efficiency similar to those noted between the ETX-II and MEV-75 systems can be anticipated. 


\section{VEHICLE PERFORMANCE}

A comparison of the expected vehicle performance using the different drivetrains was made using the SIMPLEV Version 2.0 electric vehicle simulation code. The characteristics of the vehicle simulated appear in Table 2, and are similar to the BMW-E1 vehicle which was developed for European markets. Due to inadequate information regarding some of the BMW-El parameters (e.g. transmission gear ratio, voltage and current limits, and tire rolling radius), some judgement was used in order to provide the required simulation input parameters. Therefore, it should be noted that the simulation results are not necessarily representative of the BMW-E1 vehicle. However, the simulation results employing different electric driveline configurations can be compared relative to each other. The maximum torque for the ETX-II, DSEP and MEV motors was scaled such that each motor had the same peak power as the Unique/BMW system. Additionally, the motor-to-wheels gear reductions were specified to give a maximum vehicle speed of $120 \mathrm{~km} / \mathrm{h}(75 \mathrm{mph})$ at each motor's maximum speed. The motor torque scaling factors, resulting motor characteristics, and transmission gear ratios used in the simulations for each driveline are shown in Table 3. The effects on the motor characteristics of the scaling methodology used can be seen in Figures 9 and 10. Figure 9 shows the resultant torque vs speed characteristics of each technology. None of the DOE AC systems exhibit the high torque at the lower speeds that the Unique Mobility/BMW system does. However, as can be seen in Figure 10, the resultant scaling results in the same peak power rating for each technology, although each attains its peak power at a different speed. Because of the methodology used to estimate the transmission gear ratios, each motor configuration attains its peak power at correspondingly different vehicle speeds.

The maximum effort acceleration results of the simulation are shown in Figures 11 and 12 for each of the represented technologies. The MEV technology gives vehicle acceleration similar to the Unique/BMW system. As anticipated, the systems having the highest torque produce the best vehicle acceleration times, particularly at the lower speeds. As shown in Figure 11, these systems accelerate the vehicle more rapidly than the lower torque systems. Also, the acceleration for the high torque systems is not nearly as 
Table 2. Assumed BMW-El vehicle characteristics used in simulation for comparing electric drive systems.

Vehicle Weight

Drag Coefficient

Frontal Area

Tire coefficient

Tire rolling radius
$1043 \mathrm{~kg}$ .32

$1.97 \mathrm{~m}^{2}$

.0095

$.281 \mathrm{~m}$
(2300 1b)

$21.4 \mathrm{ft}^{2}$

11.05 in

Table 3. Parameters used in scaling each of the motors to the simulated vehicle.

\begin{tabular}{|c|c|c|c|c|}
\hline Electric Drive & $\begin{array}{l}\text { Motor } \\
\text { Torque } \\
\text { Scaling } \\
\text { Factor }\end{array}$ & $\begin{array}{l}\text { Motor } \\
\text { Scaled Peak } \\
\text { Torque O Speed } \\
\text { (Nm C rpm) }\end{array}$ & $\begin{array}{l}\text { Motor } \\
\text { Scaled Peak } \\
\text { Power o Speed } \\
\text { (kW O rpm }\end{array}$ & $\begin{array}{l}\text { Gear } \\
\text { Ratio }\end{array}$ \\
\hline UNIQ/BMW & 1.00 & $150 \odot 0$ & $30.4 @ 2000$ & 7.01 \\
\hline ETX-II & .56 & $99.6 \odot 0$ & $30.4 \odot 6000$ & 9.65 \\
\hline MEV - 75 & .51 & $65.3 \odot 0$ & $30.4 \odot 7000$ & 11.40 \\
\hline DSEP & .61 & $48.5 \bigcirc 5000$ & $30.3 \odot 7000$ & 10.52 \\
\hline
\end{tabular}




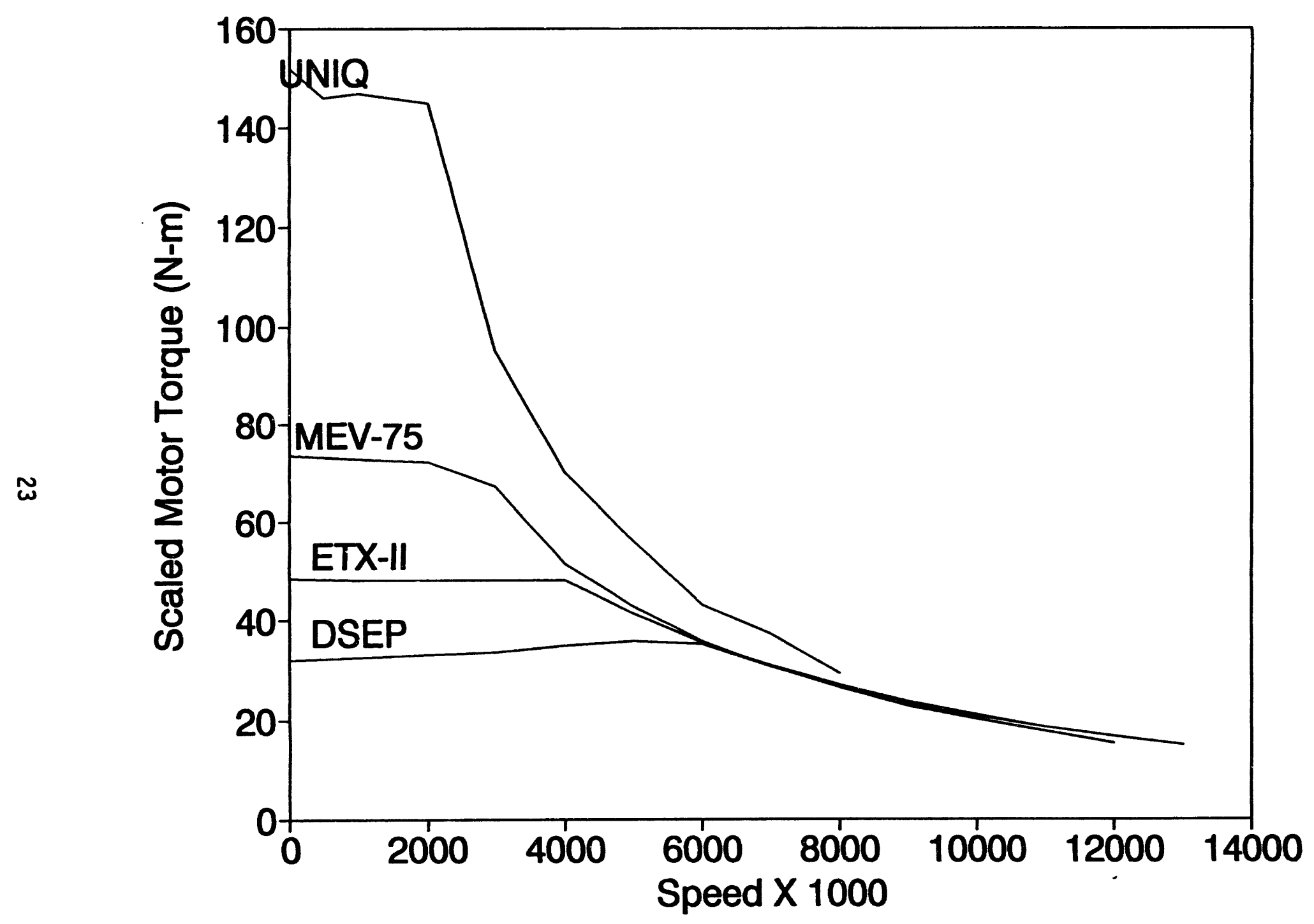

Figure 9. Maximum torque-speed envelope of the scaled motors used in the simulation. 


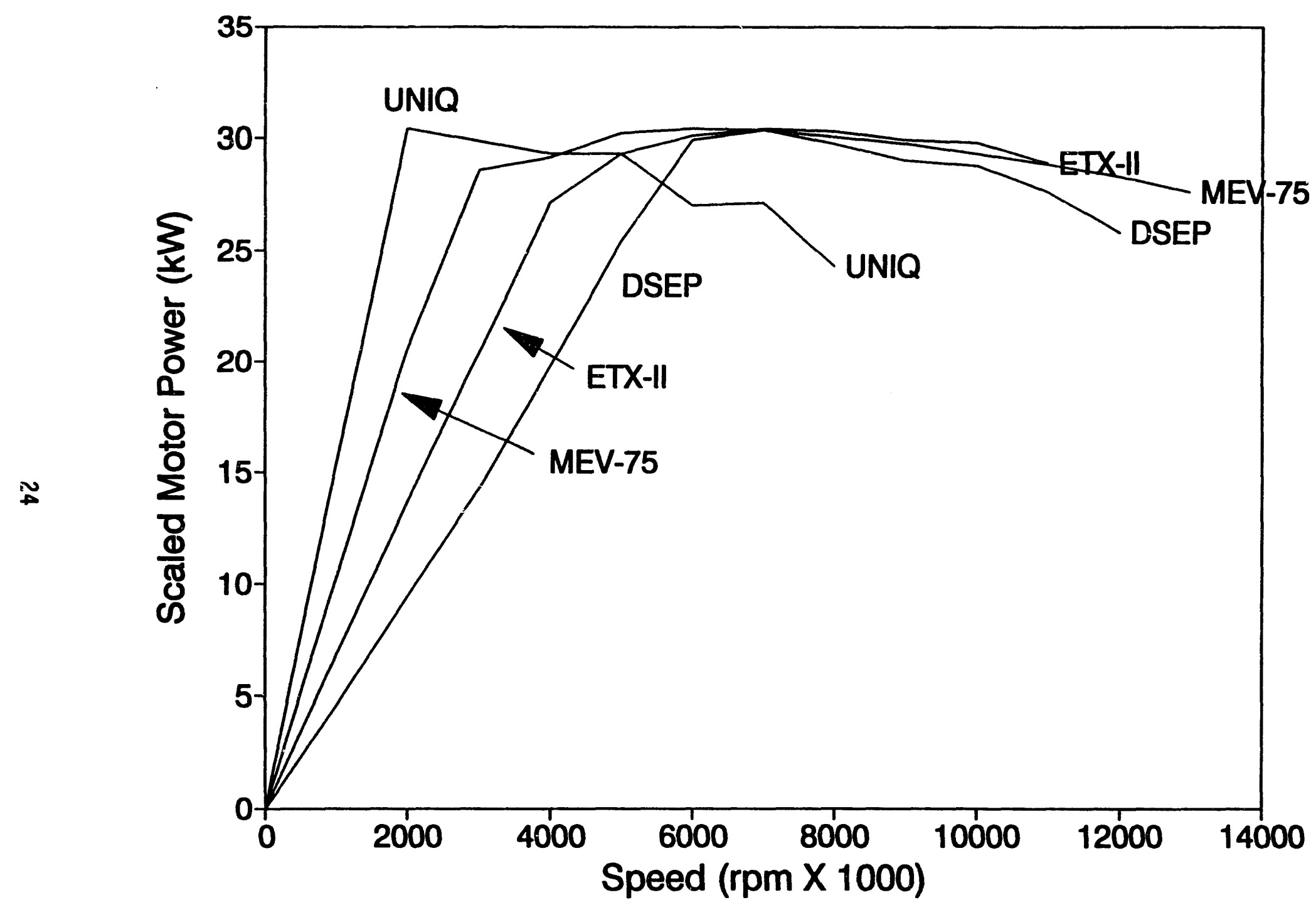

Figure 10. Peak power versus speed characteristics of the scaled motors used in the simulation. 


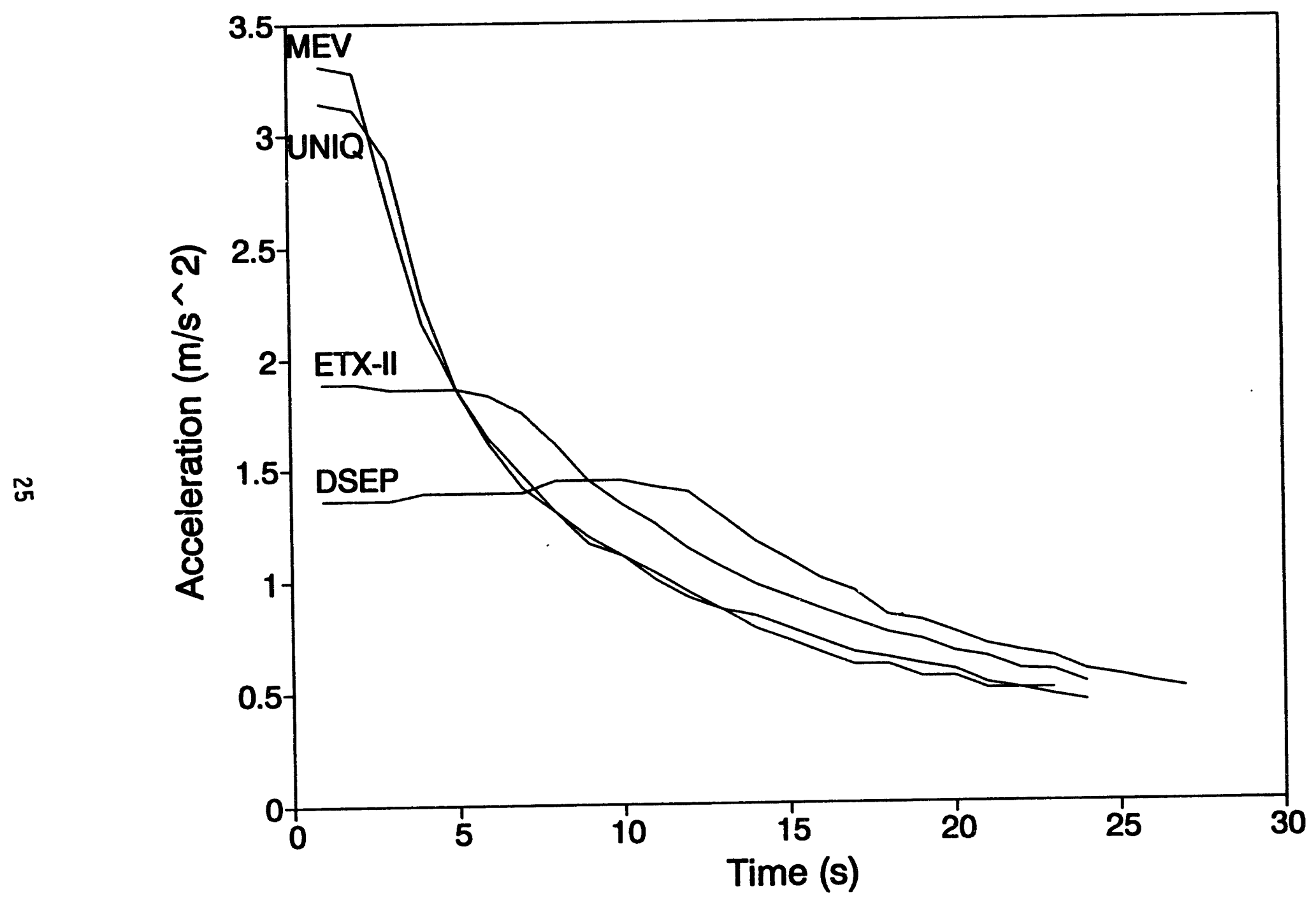

Figure 11. Acceleration of a hypothetical vehicle using each of the electric drive system technologies. 


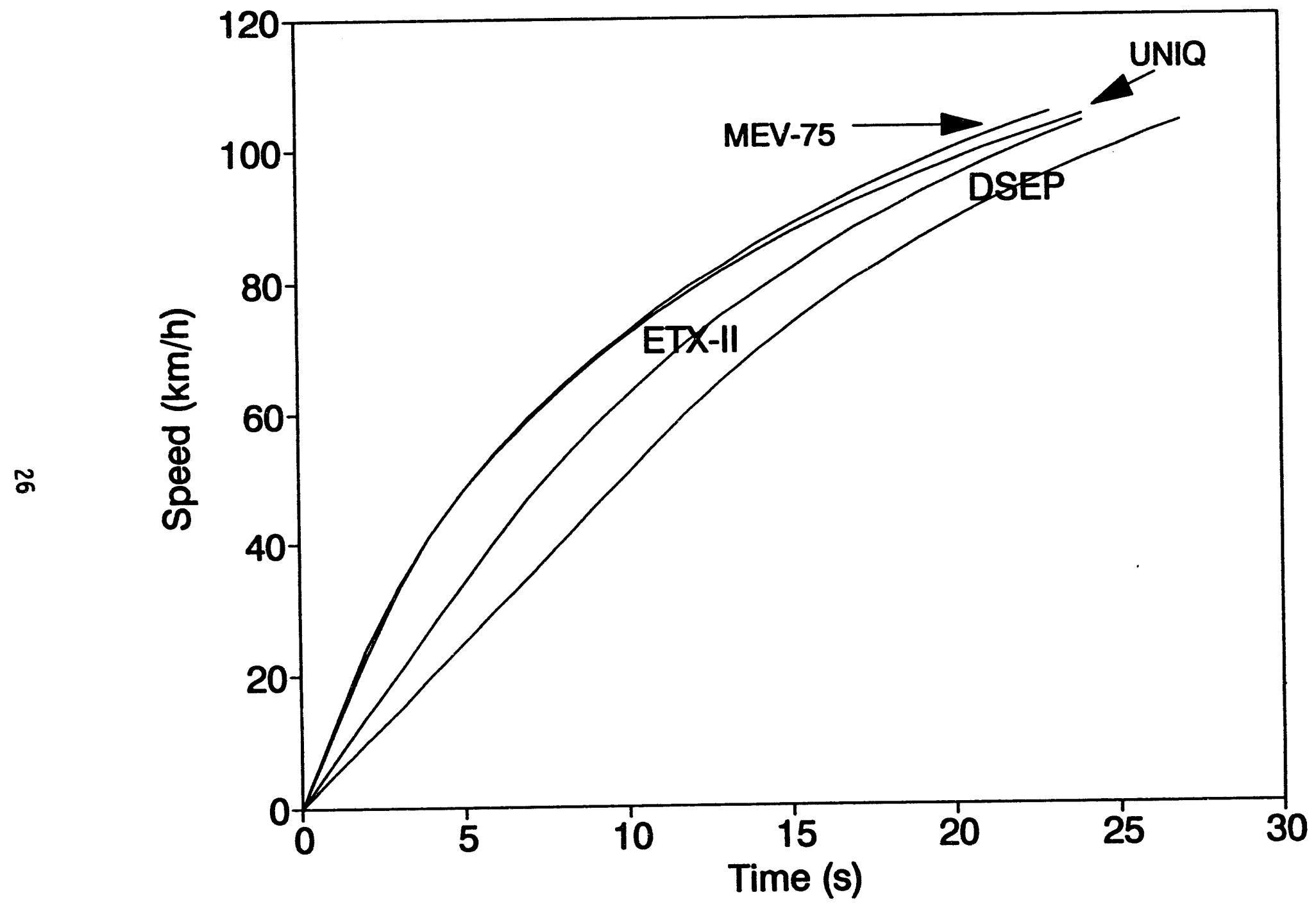

Figure 12. Maximum effort acceleration comparison of technologies in a hypothetical vehicle. 
constant over the speed range, and drops off rapidly when the constant power portion of the motor's envelope is reached. The desirability of this characteristic is debatable. The Unique and MEV drivelines offer rapid acceleration up to approximately 30 to $40 \mathrm{~km} / \mathrm{h}$, but this comes at the expense of the driver perception of a much slower acceleration at higher speeds. The ETX-II and DSEP technologies with their respective torque characteristics, exhibit slower acceleration at the lower speeds, but with smaller differences in acceleration performance with vehicle speed being perceived by the driver. It is important to note that although the Unique Mobility/BMW drive has a lower maximum motor speed and rapid torque fall off, equivalent acceleration performance of the higher speed MEV drive can be obtained without the need for multiple gear reductions.

The relative energy consumption and average efficiency for each of these technologies was calculated on the Federal Urban and Highway Driving Cycles (FUDS and FHDS) and are shown in Table 4. The Unique Mobility/BMW system is slightly less efficient than the DOE AC designs in the hypothesized application, which results in a corresponding increase in gross energy consumption (i.e. regeneration is not included). However, it should be recognized that the differences in these efficiency and energy consumption values are relatively small and likely within the range of variability from one vehicle design to another.

It was observed during the simulations that while the DOE AC systems were able to complete the FUDS and FHDS within the allowable speed-time tolerance $( \pm 3.2 \mathrm{~km} / \mathrm{h}$ within $\pm \mathrm{l} \mathrm{s}$ of the target speed), they were not able to match the target speed vs time profile as well as the BMW and scaled MEV systems. This is mainly due to the lower peak torques (and lower peak power) that the ETX-II and DSEP scaled systems are able to provide during vehicle acceleration at the lower vehicle speeds. 
Table 4. Comparison of drive system technologies in a hypothetical vehicle.

Electric Drive

System

Unique Mobility/BMW

ETX-II Technology

MEV Technology

DSEP Technology

\section{FUDS}

Gross

Energy

Consumption Efficiency

(Wh/ km)

(\%)

113

110

106

123
85

87

90

77
FHDS

Gross

Energy Average

Consumption Efficiency

(Wh $/ \mathrm{km})$

$(\%)$

108

108

99

112
86

86

94

83 


\section{CONCLUSIONS}

The Unique Mobility electric motor/controller technology as represented by the drive system under development for BMW exhibits many desirable characteristics for electric vehicle propulsion applications. On the basis of weight per unit peak power, the Unique Mobility technology is essentially the same as that of the Modular Electric Vehicle Program $75 \mathrm{Hp}$ (MEV-75) system. Volumetrically (volume per unit peak power basis), the Unique Mobility/BMW system is slightly larger than the MEV-75 system and essentially equal to the ETX-II system.

The motor torque-speed characteristics of Unique's system are appropriate for electric vehicle applications and yield vehicle acceleration performance equivalent to the MEV drive system technology.

The system efficiency characteristics of the Unique Mobility technology electric drive are such that overall system efficiencies (and energy consumption) of a properly designed electric vehicle would be comparable to the best of alternative technology drive systems.

Since the Unique Mobility technology offers most of the advantages of the AC systems cited in the trade-off analysis performed by Ford during the first Phase of the Modular Electric Vehicle Program, the Unique Mobility technology would likely have fared well if it had been included in that analysis. However, sufficient information on cost for the MEV AC induction motor system or the Unique Mobility system are not available to draw firm conclusions on this issue.

A1 though the Unique Mobility/BMW motor is a lower maximum speed than the DOE AC motors, a multiple step transmission is not required to provide acceptable vehicle acceleration performance and a top speed of $120 \mathrm{~km} / \mathrm{h}(75$ $\mathrm{mph})$. This is due to the high torque at low speeds of the Unique Mobility/BMW motor, and its ability to attain the peak power at relatively low motor speeds. 


\section{BIBLIOGRAPHY}

Ford Motor Company, Modular Electric Vehicle Program - (MEVP) Phase I

Technical Report, DOE/ID-13019-1, March 1991

Ford Motor Company, Single-Shaft Electric Propulsion System Technology Development Program - ETX-II Phase II Technical Report, DOE/NV-10418-2, Apri1 1989

Ford Motor Company, Single-Shaft Electric Propulsion System Technology Development Program - ETX-II Final Technical Report, DOE/NV/10418-3, October 1990

King, R. D. and Konrad, C. E., Advanced On-Road Electric Vehicle AC Drives Concept to Reality, Proceedings of the Eleventh International Electric Vehicle Symposium, Florence, Italy, 1992

Product specification and data sheets, Unique Mobility, Inc., Golden, c0.

Faust, K., Goubeau, A., and Scheuerer, K., Introduction to the BMW-E1, Society of Automotive Engineers paper number 920443.

Goubeau, A., Scheuerer, K., and Juraschek, S., Advancements in Electric Propulsion Systems at BMW, Paper No. $92 \mathrm{CO} 37$.

Letter, W. G. Rankin to G. H. Cole, October 27, 1992.

Burke, A. F., Electric Vehicle Propulsion and Battery Technology 1975-1995.

Dual-Shaft Electric Propulsion (DSEP) Technology Development Program, DOE/NV10366-21, August 1992

Telephone conversations, W. G. Rankin and G. H. Cole, October-November 1992.

Telephone conversation, C. Cambier, Unique Mobility and G. H. Cole, January $13,1993$. 

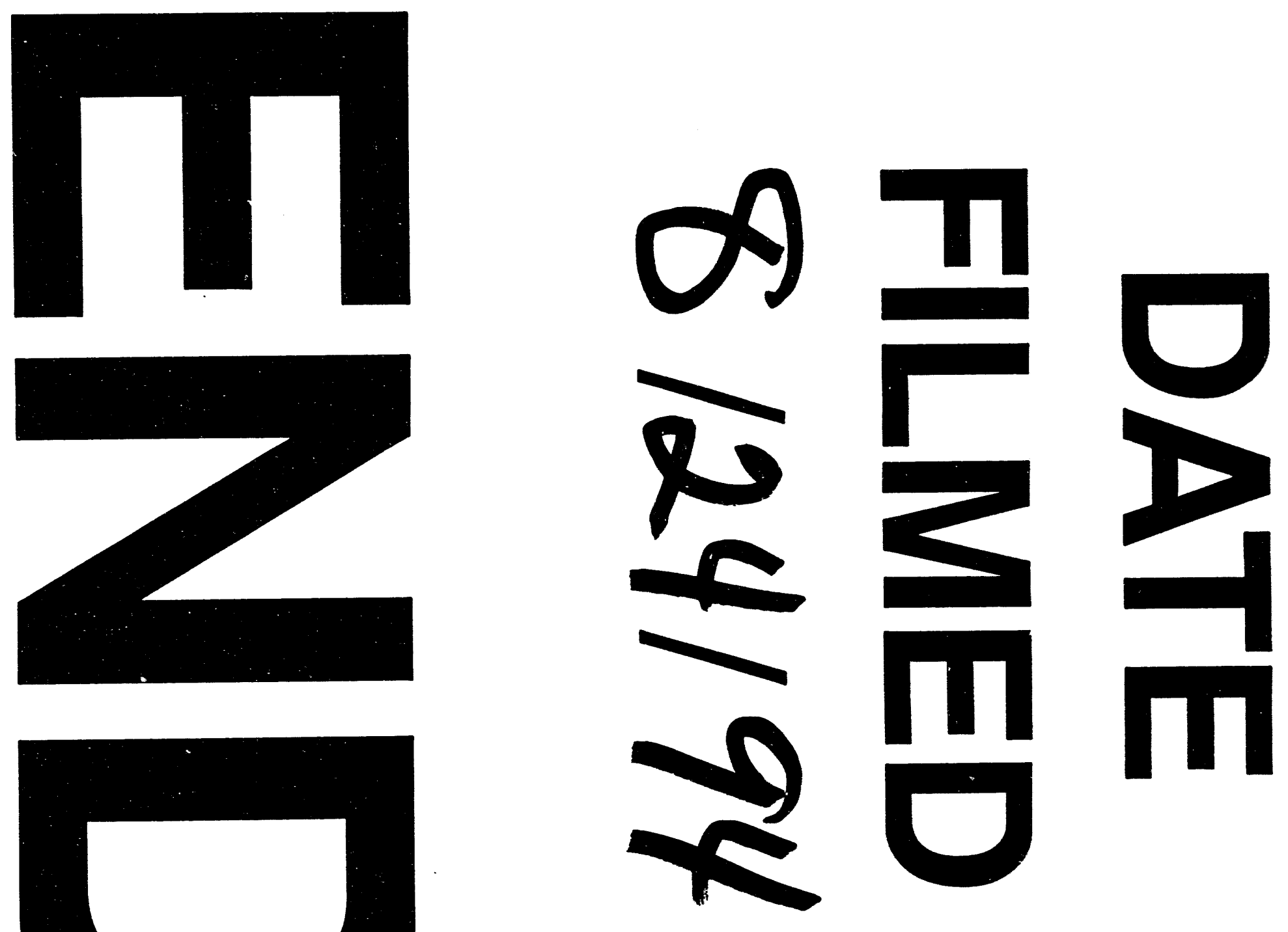
